\title{
Association of physician payment model and team-based care with timely access in primary care: a population-based cross-sectional study
}

\author{
Tara Kiran MD MSc, Michael E. Green MD MPH, Yvonne DeWit MSc, Shahriar Khan MSc, \\ Sue Schultz MSc, Alexander Kopp BA, Naira Yeritsyan MD MPH, Haj Ali Wissam MPH, \\ Richard H. Glazier MD MPH
}

\section{Abstract}

Background: It is unclear how patient-reported access to primary care differs by physician payment model and participation in teambased care. We examined the association between timely and after-hours access to primary care and physician payment model and participation in team-based care, and sought to assess how access varied by patient characteristics.

Methods: We conducted a cross-sectional analysis of adult (age $\geq 16 \mathrm{yr}$ ) Ontarians who responded to the Ontario Health Care Experience Survey between January 2013 and September 2015, reported having a primary care provider and agreed to have their responses linked to health administrative data. Access measures included the proportion of respondents who reported same-day or next-day access when sick, satisfaction with time to appointment when sick, telephone access and knowledge of an after-hours clinic. We tested the association between practice model and measures of access using logistic regression after stratifying for rurality.

Results: A total of 33665 respondents met our inclusion criteria. In big cities, respondents in team and nonteam capitation models were less likely to report same-day or next-day access when sick than respondents in enhanced fee-for-service models (team capitation $43 \%$, adjusted odds ratio [OR] 0.88, 95\% confidence interval [Cl] 0.79-0.98; nonteam capitation 39\%, adjusted OR 0.78, 95\% Cl 0.70-0.87; enhanced fee-for-service $46 \%$ [reference]). Respondents in team and nonteam capitation models were more likely than those in enhanced fee-for-service models to report that their provider had an after-hours clinic (team capitation $59 \%$, adjusted OR 2.59, 95\% Cl 2.39-2.81; nonteam capitation 51\%, adjusted OR 1.90, 95\% Cl 1.76-2.04; enhanced fee-for service 34\% [reference]). Patterns were similar for respondents in small towns. There was minimal to no difference by model for satisfaction with time to appointment or telephone access.

Interpretation: In our setting, there was an association between some types of access to primary care and physician payment model and team-based care, but the direction was not consistent. Different measures of timely access are needed to understand health care system performance.

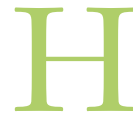
ealth care systems with strong primary care have better health outcomes, lower costs and fewer inequities. ${ }^{1}$ First-contact access is one of the pillars of primary care, ${ }^{2}$ yet, in Canada, timely access to primary care continues to be a challenge. For example, only $43 \%$ of patients in Canada report being able to get an appointment the same day or the next day when sick, compared to $77 \%$ in the Netherlands, the top-ranked country for this type of access in the Commonwealth Fund's 2016 survey. ${ }^{3}$ Canada also has the highest rates of emergency department use, with many patients reporting they went to the emergency department for a condition that could have been managed in primary care. ${ }^{3}$ Policy-makers have hoped to address some of these issues by supporting practices to transition to medical homes. ${ }^{4,5}$
Medical homes typically incorporate blended payment for physicians, a focus on quality and safety, and mechanisms for enhanced access. ${ }^{6,7}$ In Ontario, reforms have included options for physicians to transition from fee-for-service to blended capitation and to apply for funding for nonphysician health

Competing interests: Tara Kiran was the Board Chair for the St. Michael's Hospital Academic Family Health Team from 2014 to 2018. No other competing interests were declared.

This article has been peer reviewed.

Correspondence to: Tara Kiran, tara.kiran@utoronto.ca

CMAJ Open 2020. DOI:10.9778/cmajo.20190063 
care professionals to join their team. ${ }^{8}$ Under the fee-forservice model, physicians are paid a set fee per visit or procedure, whereas the capitation model provides a set fee per person per year. Theoretically, capitation supports the care of patients with multiple chronic conditions, incentivizing proactive follow-up, non-visit-based care and addressing multiple issues at 1 appointment. However, capitation provides little incentive to see a high volume of patients, and reduced access is a known concern. ${ }^{9}$ In contrast, sharing the care with nonphysician health care professionals is a strategy known to improve access. ${ }^{10-12}$

Little research to date has evaluated the association between access and physician payment model and organization. In the present study, we examined the association between timely and after-hours access and physician payment and participation in team-based care. We also sought to assess how access varied by patient characteristics.

\section{Methods}

\section{Setting and context}

Ontario is Canada's largest province, with a population of 14.3 million in 2018. ${ }^{13}$ Primary care physician services are fully insured for all permanent residents through the Ontario Health Insurance Plan, with no copayments or deductibles. Primary care physician payment and organization have shifted over the last 15 years. In 2002, most physicians worked independently and billed fee-for-service. ${ }^{14}$ Now, most physicians practise in a Patient Enrolment Model, where they are organized in groups, formally enrol patients, are remunerated via blended payments and are mandated to provide after-hours coverage. ${ }^{8}$

There are 3 dominant Patient Enrolment Models: enhanced fee-for-service ( $85 \%$ fee-for-service, $15 \%$ capitation and bonuses, no funding for nonphysician health care professionals), nonteam capitation (20\% fee-for-service, $80 \%$ capitation and bonuses, no funding for nonphysician health care professionals) and team capitation (20\% fee-for-service, $80 \%$ capitation and bonuses, and funding for nonphysician health care professionals). There are quotas for the number of physicians who can enter a capitation model. Applications for team funding were reviewed and approved by the provincial government between 2005 and 2012 but not since.

About 1 in 6 Ontarians do not receive care from a physician practising in a Patient Enrolment Model. ${ }^{15}$ Ontario includes densely populated urban areas, smaller towns and cities, and rural and remote regions with unique health care service challenges. Patient Enrolment Models are unevenly distributed across the province. ${ }^{16}$

\section{Study design and population}

We conducted a cross-sectional analysis of Ontario residents to understand the determinants of timely access to primary care, including patient characteristics, type of physician payment model and rurality. We included Ontarians aged 16 years or more who responded to the provincial Health Care Experience Survey (www.health.gov.on.ca/en/common/ healthcareexperiencesurvey.asp), between Jan. 1, 2013, and Sept. 30, 2015, agreed to have their responses linked with health administrative data, reported having a primary care provider, had valid provincial health insurance and had had contact with the health care system in the previous 7-9 years, depending on the date of completion of the survey. These data sets were linked by means of unique encoded identifiers and analyzed at ICES. Our study did not include patients who visited a community health centre, an older practice model serving $1 \%-2 \%$ of Ontario's population, ${ }^{17}$ owing to a small number of survey responses.

\section{Measures of timely access}

The Health Care Experience Survey is a voluntary telephone survey introduced by Ontario's Ministry of Health and LongTerm Care in 2012 to understand the public's experience with various aspects of the health care system, including primary care. The survey is conducted by the Institute for Social Research at York University. The public is sampled by means of the Registered Persons Database, which contains personal and demographic data for all current and previous health plan registrants. About 11200 interviews lasting 15 minutes are conducted annually with the use of a sampling frame that accounts for geography. The survey runs continuously, with data provided to government in 3-month waves. Our study includes data from wave 2 (first wave with full survey implemented) to wave 16 (most recent data linked to administrative databases). The response rates in these waves range from $46 \%$ to $56 \%$. A copy of the survey is provided in Appendix 1, available at www.cmajopen.ca/content/8/2/E328/suppl/DC1.

Our primary analysis included 4 questions related to timely and after-hours access to primary care:

- How many days did it take from when you first tried to see your provider to when you actually saw him/her or someone else in the office?

- How would you rate the length of time it took between making the appointment and the actual visit?

- How often did your provider or someone else in the office speak to you when you called or get back to you the same day?

- Not including hospital emergency departments, does your provider have an after-hours clinic where patients can be seen by or talk to a doctor or nurse when the practice is closed?

We analyzed other responses related to email use and online booking descriptively given the small number of affirmative responses. For each question, we excluded missing and "don't know/refused" responses from the denominator with the exception of after-hours awareness, where "don't know/ refused" was coded together with "no."

\section{Other variables}

We obtained the following demographic variables from the Health Care Experience Survey: self-rated health, level of education, financial situation and language spoken most often at home. We obtained other demographic variables from administrative data. We determined age, sex, and postal code from the Registered Persons Database. We used postal code to 
derive neighbourhood income quintile (an area-based proxy for poverty used only when comparing demographic characteristics between survey respondents and the general population). We calculated rurality using the Rurality Index for Ontario $(\leq 9=$ urban, $10-39=$ small town, $\geq 40=$ rural).${ }^{18} \mathrm{We}$ assessed health plan registration within the previous 10 years, as many respondents were newcomers to Canada. ${ }^{19}$ We used the Johns Hopkins Adjusted Clinical Groups software to measure comorbidity using Aggregated Diagnosis Groups and morbidity using Resource Utilization Bands, assigned based on similar health care use, each calculated with data from a 2-year period.

We assigned survey respondents to a Patient Enrolment Model based on enrolment tables and categorized them as enrolled to a physician in enhanced fee-for-service (Family Health Group or Comprehensive Care Model), nonteam capitation (Family Health Organization or Family Health Network) or team capitation (Family Health Team), or as not enrolled. Enrolment tables are highly accurate, as the information in the tables is used for physician remuneration.

\section{Statistical analysis}

We compared demographic characteristics of survey respondents to those of the general population of Ontario. We conducted bivariate analysis to examine the relation between timely access and both respondent demographic characteristics and practice model. We stratified bivariate analyses by rurality because we hypothesized a priori that the relation between practice model and access may differ by rurality. We used multivariable logistic regression to understand the relation between practice model and timely access after controlling for respondent demographic characteristics. We included variables that we hypothesized a priori as potential confounders (age, sex, education, self-reported tight financial situation, self-rated health, comorbidity and health plan registration within the previous 10 years. We did not include Resource Utilization Band as it was significantly correlated with Aggregated Diagnosis Group and likewise excluded language as it was significantly correlated with recent health plan registration. We initially included rurality in the model as well as an interaction term for rurality and practice model. There was a significant interaction between rurality and practice model, so we ran separate logistic regression models for big cities, small towns and rural areas.

\section{Ethics approval}

The use of data in this project was authorized under section 45 of Ontario's Personal Health Information Protection Act, which does not require review by a research ethics board.

\section{Results}

A total of 39665 Ontarians responded to the Health Care Experience Survey between January 2013 and September 2015, with 36792 (92.8\%) agreeing to have their responses linked to health administrative data. Compared to the general population, survey respondents were older, had more comorbidities and were more likely to reside in a rural area, live in a higher-income neighbourhood and be a long-term resident of Ontario (Appendix 2, Supplemental Table S1, available at www.cmajopen.ca/content/8/2/E328/suppl/DC1).

We analyzed data for 33665 people who met our inclusion criteria (Figure 1). Respondents' characteristics differed by practice model (Table 1). For example, a higher proportion of respondents in team capitation models than in other models lived in rural areas, whereas a lower proportion of respondents in capitation models were recent registrants or spoke a language other than English.

Of the 17117 respondents who reported seeing their own provider or someone else in office when they were sick or had a health concern, $6684(39.0 \%)$ reported getting a same-day or next-day appointment (Figure 1). Of the 2405 respondents who responded to the question about satisfaction with wait time, $1652(68.7 \%)$ rated the length of the time they waited for an appointment when sick as about right. A total of $14223 / 18430$ respondents (77.2\%) reported that their provider always or often responded to a telephone call about a medical concern the same day, and $13858 / 33665$ (41.2\%) said their physician had an after-hours clinic.

Respondents living in rural areas, as well as those with selfreported fair health and a tight, very tight or poor financial situation generally reported poorer access across all 4 questions (Appendix 2, Supplemental Table S2). New residents of Ontario and those who spoke a language other than English at home reported higher same-day or next-day access when sick but poorer access via telephone, no after-hours clinics and lower satisfaction with time to the appointment. Less than $4 \%$ of respondents reported emailing with their physician in the previous 12 months, and $21.3 \%$ reported being able to book an appointment online or via email.

A total of $19.6 \%$ of respondents from waves 15 and 16 reported good access for all 4 questions about access (Figure 2). The proportion reporting good access for all questions was lowest in rural areas $(7.2 \%)$ and among those not enrolled (11.9\%).

Table 2 indicates the overlap in responses for access to care when sick and satisfaction with time to the appointment. Of the 881 respondents who reported a same-day or next-day visit when sick, $806(91.5 \%)$ were satisfied with time to the visit. In contrast, $806(50.1 \%)$ of the 1609 people who reported being satisfied with time to the visit reported having a same-day or next-day appointment.

Table 3 summarizes the crude responses to the 4 questions by physician practice model, stratified by rurality. Respondents in rural areas reported poorer access generally, especially access to care when sick and satisfaction with time to appointment. There was variation in access by physician practice model, even within rural strata, and differences between models varied by rurality.

Figure 3 presents the log of the adjusted odds ratio (OR) for respondents reporting favourable access by practice model, stratified by rurality. In big cities, respondents in team and nonteam capitation models were less likely than those in enhanced fee-for-service models to report same-day or next-day access when sick, even after adjustment for 


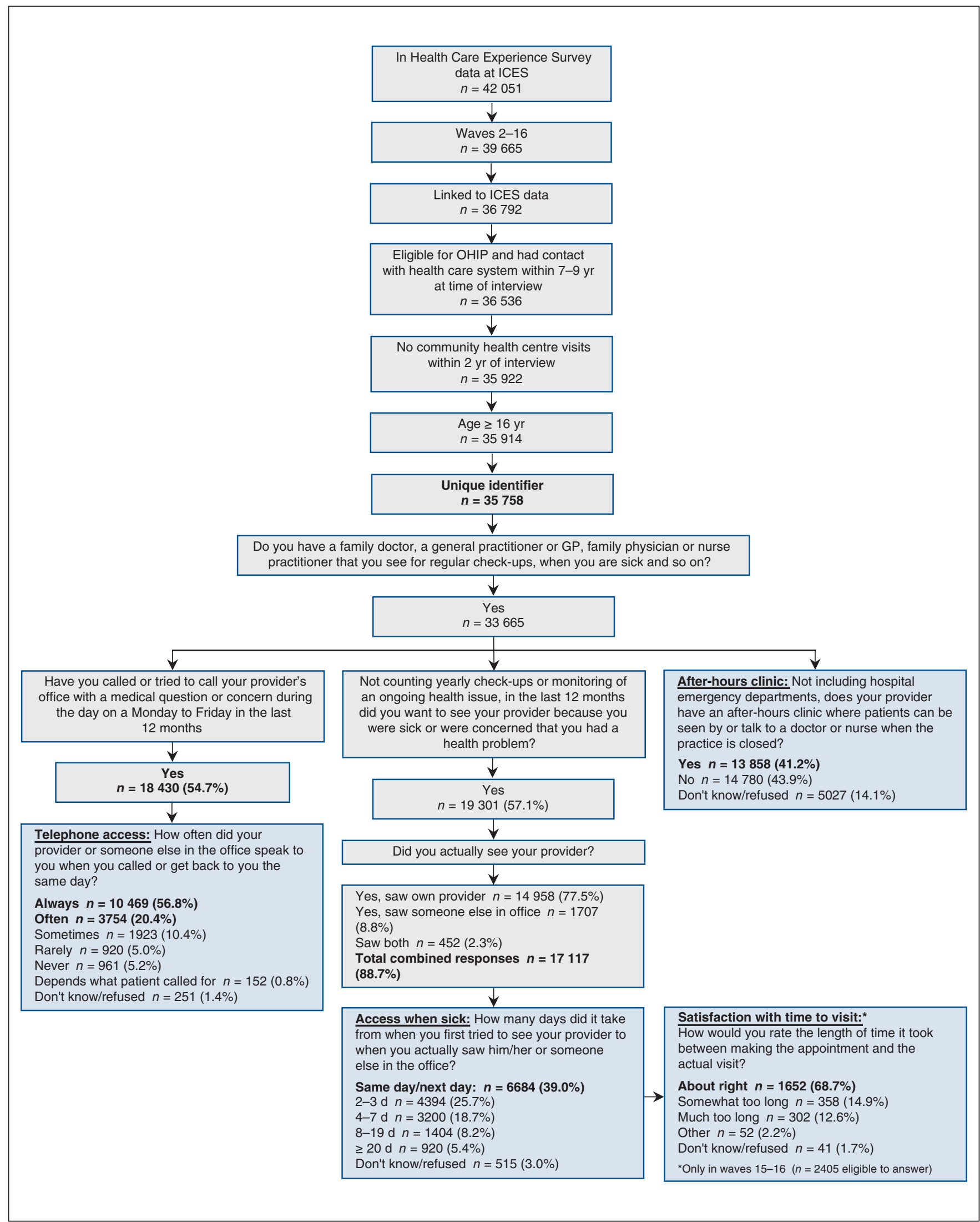

Figure 1: Flow diagram showing selection of survey respondents included in study and responses to the 4 questions related to timely access to primary care. Note: OHIP = Ontario Health Insurance Plan. 


\begin{tabular}{|c|c|c|c|c|c|}
\hline \multirow[b]{2}{*}{ Characteristic } & \multicolumn{5}{|c|}{ Practice model; no. $(\%)$ of respondents } \\
\hline & $\begin{array}{c}\text { Team capitation } \\
n=11657\end{array}$ & $\begin{array}{c}\text { Nonteam } \\
\text { capitation } \\
n=8882\end{array}$ & $\begin{array}{c}\text { Enhanced fee } \\
\text { for service } \\
n=7892\end{array}$ & $\begin{array}{l}\text { Not enrolled } \\
n=3872\end{array}$ & $\begin{array}{c}\text { Total } \\
n=32303\end{array}$ \\
\hline \multicolumn{6}{|l|}{ Sex } \\
\hline Female & 6913 (59.3) & $5218(58.7)$ & $4542(57.6)$ & 2051 (53.0) & $18724(58.0)$ \\
\hline Male & $4744(40.7)$ & $3664(41.3)$ & $3350(42.4)$ & $1821(47.0)$ & $13579(42.0)$ \\
\hline \multicolumn{6}{|l|}{ Age, yr } \\
\hline $16-49$ & $4438(38.1)$ & $3590(40.4)$ & $3764(47.7)$ & 2050 (52.9) & $13842(42.9)$ \\
\hline $50-64$ & 3739 (32.1) & $2770(31.2)$ & $2326(29.5)$ & $1081(27.9)$ & $9916(30.7)$ \\
\hline $65-79$ & $2765(23.7)$ & $1990(22.4)$ & 1435 (18.2) & $604(15.6)$ & $6794(21.0)$ \\
\hline$\geq 80$ & $715(6.1)$ & $532(6.0)$ & $367(4.7)$ & $137(3.5)$ & $1751(5.4)$ \\
\hline \multicolumn{6}{|l|}{ Rurality } \\
\hline Big city & 4815 (41.3) & $6145(69.2)$ & $6137(77.8)$ & 2563 (66.2) & $19660(60.9)$ \\
\hline Small town & $4138(35.5)$ & $2107(23.7)$ & $1372(17.4)$ & $770(19.9)$ & $8387(26.0)$ \\
\hline Rural & $2422(20.8)$ & $589(6.6)$ & $326(4.1)$ & $446(11.5)$ & $3783(11.7)$ \\
\hline Missing & $282(2.4)$ & $41(0.5)$ & $57(0.7)$ & $93(2.4)$ & $473(1.5)$ \\
\hline \multicolumn{6}{|l|}{$\begin{array}{l}\text { Health plan registrant within } \\
\text { previous } 10 \mathrm{yr}\end{array}$} \\
\hline No & $11540(99.0)$ & $8716(98.1)$ & $7420(94.0)$ & $3581(92.5)$ & $31257(96.8)$ \\
\hline Yes & $117(1.0)$ & $166(1.9)$ & $472(6.0)$ & $291(7.5)$ & $1046(3.2)$ \\
\hline \multicolumn{6}{|l|}{$\begin{array}{l}\text { No. of Aggregated Diagnosis } \\
\text { Groups }\end{array}$} \\
\hline 0 (lowest) & $535(4.6)$ & $296(3.3)$ & $179(2.3)$ & $322(8.3)$ & $1332(4.1)$ \\
\hline $1-5$ & $5441(46.7)$ & $3803(42.8)$ & $2738(34.7)$ & $1741(45.0)$ & $13723(42.5)$ \\
\hline $6-9$ & $4617(39.6)$ & $3837(43.2)$ & $3837(48.6)$ & $1448(37.4)$ & $13739(42.5)$ \\
\hline$\geq 10$ (highest) & $1064(9.1)$ & $946(10.7)$ & $1138(14.4)$ & $361(9.3)$ & $3509(10.9)$ \\
\hline \multicolumn{6}{|l|}{ Resource Utilization Bands } \\
\hline 0 (low) & $525(4.5)$ & $290(3.3)$ & $179(2.3)$ & $318(8.2)$ & $1312(4.1)$ \\
\hline 1 & $552(4.7)$ & $361(4.1)$ & 264 (3.3) & $212(5.5)$ & $1389(4.3)$ \\
\hline 2 & $1933(16.6)$ & $1350(15.2)$ & $982(12.4)$ & $689(17.8)$ & $4954(15.3)$ \\
\hline 3 & $6066(52.0)$ & $4966(55.9)$ & $4516(57.2)$ & $1891(48.8)$ & $17439(54.0)$ \\
\hline 4 & $1823(15.6)$ & $1388(15.6)$ & $1436(18.2)$ & $579(15.0)$ & $5226(16.2)$ \\
\hline 5 (high) & $758(6.5)$ & $527(5.9)$ & $515(6.5)$ & $183(4.7)$ & $1983(6.1)$ \\
\hline \multicolumn{6}{|l|}{ Self-reported health } \\
\hline Excellent & $2140(18.4)$ & $1701(19.2)$ & 1435 (18.2) & $766(19.8)$ & $6042(18.7)$ \\
\hline Very good & $4389(37.7)$ & $3390(38.2)$ & $2879(36.5)$ & $1424(36.8)$ & $12082(37.4)$ \\
\hline Good & $3265(28.0)$ & $2471(27.8)$ & $2333(29.6)$ & $1074(27.7)$ & $9143(28.3)$ \\
\hline Fair & $1334(11.4)$ & $931(10.5)$ & $915(11.6)$ & $428(11.1)$ & $3608(11.2)$ \\
\hline Poor & $493(4.2)$ & $354(4.0)$ & $302(3.8)$ & $159(4.1)$ & $1308(4.0)$ \\
\hline Missing & $36(0.3)$ & $35(0.4)$ & $28(0.4)$ & $21(0.5)$ & $120(0.4)$ \\
\hline \multicolumn{6}{|l|}{ Education } \\
\hline Less than high school & $1532(13.1)$ & $931(10.5)$ & $748(9.5)$ & $463(12.0)$ & $3674(11.4)$ \\
\hline High school & $2570(22.0)$ & $1848(20.8)$ & $1642(20.8)$ & $727(18.8)$ & $6787(21.0)$ \\
\hline Some college or university & $1097(9.4)$ & $755(8.5)$ & $697(8.8)$ & $343(8.9)$ & $2892(9.0)$ \\
\hline College/trade & 3085 (26.5) & $2269(25.5)$ & $1796(22.8)$ & $919(23.7)$ & $8069(25.0)$ \\
\hline Bachelor's degree & $2233(19.2)$ & $2003(22.6)$ & $1959(24.8)$ & $936(24.2)$ & $7131(22.1)$ \\
\hline Graduate/professional degree & $1061(9.1)$ & $1000(11.3)$ & $987(12.5)$ & $459(11.9)$ & 3507 (10.9) \\
\hline Missing & $79(0.7)$ & $76(0.9)$ & $63(0.8)$ & $25(0.6)$ & $243(0.8)$ \\
\hline \multicolumn{6}{|l|}{ Financial situation } \\
\hline Very comfortable & $1773(15.2)$ & $1442(16.2)$ & $1133(14.4)$ & $598(15.4)$ & $4946(15.3)$ \\
\hline Comfortable & 7257 (62.3) & $5440(61.2)$ & $4772(60.5)$ & 2279 (58.9) & $19748(61.1)$ \\
\hline Tight/very tight/poor & $2354(20.2)$ & $1726(19.4)$ & $1762(22.3)$ & $912(23.6)$ & $6754(20.9)$ \\
\hline Missing & $273(2.3)$ & $274(3.1)$ & $225(2.9)$ & $83(2.1)$ & $855(2.6)$ \\
\hline \multicolumn{6}{|l|}{ Language } \\
\hline English & $11024(94.6)$ & $7995(90.0)$ & $6440(81.6)$ & $3269(84.4)$ & $28728(88.9)$ \\
\hline Other & $9(0.1)$ & $17(0.2)$ & $21(0.3)$ & $9(0.2)$ & $56(0.2)$ \\
\hline Missing & $624(5.4)$ & $870(9.8)$ & $1431(18.1)$ & $594(15.3)$ & $3519(10.9)$ \\
\hline
\end{tabular}


respondent demographic characteristics (team capitation $43 \%$ [adjusted OR $0.88,95 \%$ confidence interval (CI) 0.79 0.98 ], nonteam capitation 39\% [adjusted OR 0.78, 95\% CI 0.70-0.87], enhanced fee-for-service 46\% [reference]).
Respondents in team and nonteam capitation models were more likely than those in enhanced fee-for-service models to report that their provider had an after-hours clinic (team capitation 59\% [adjusted OR 2.59, 95\% CI 2.39-2.81],

A

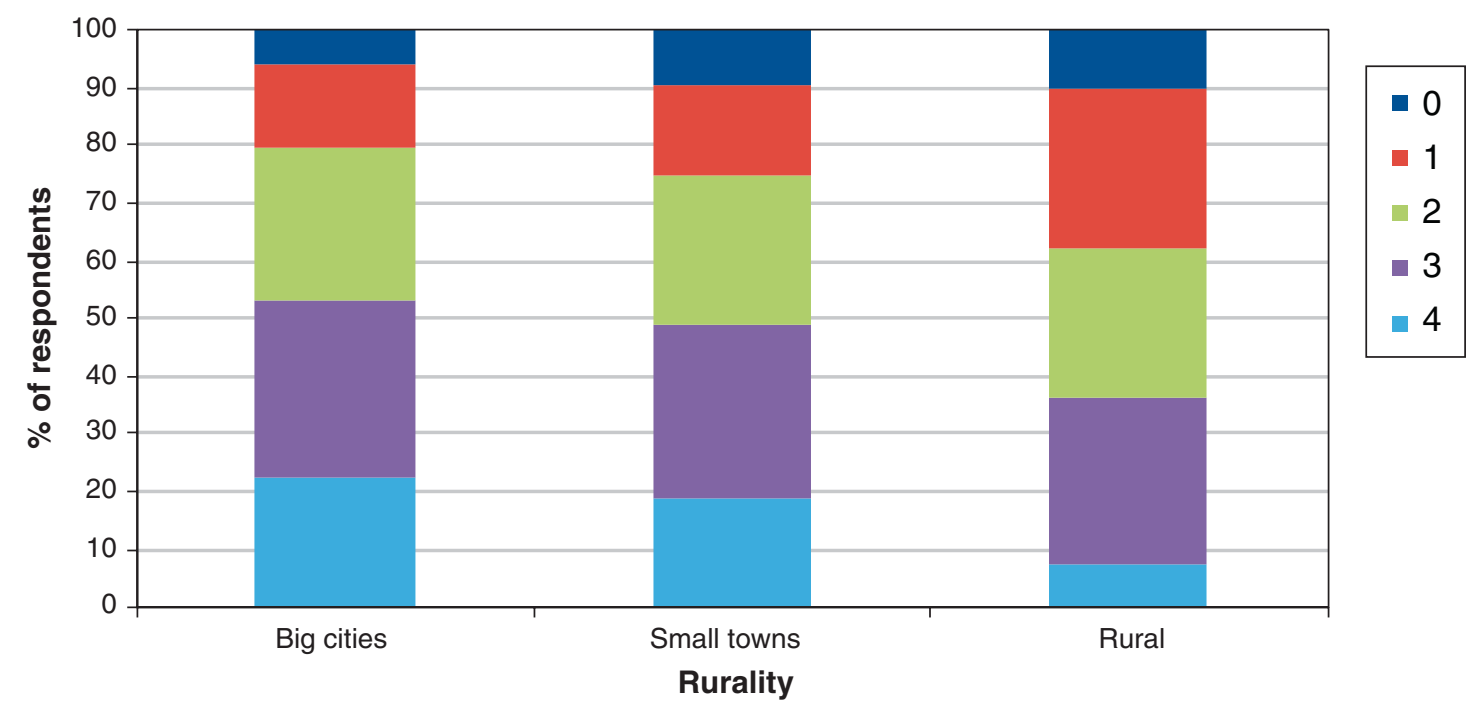

B

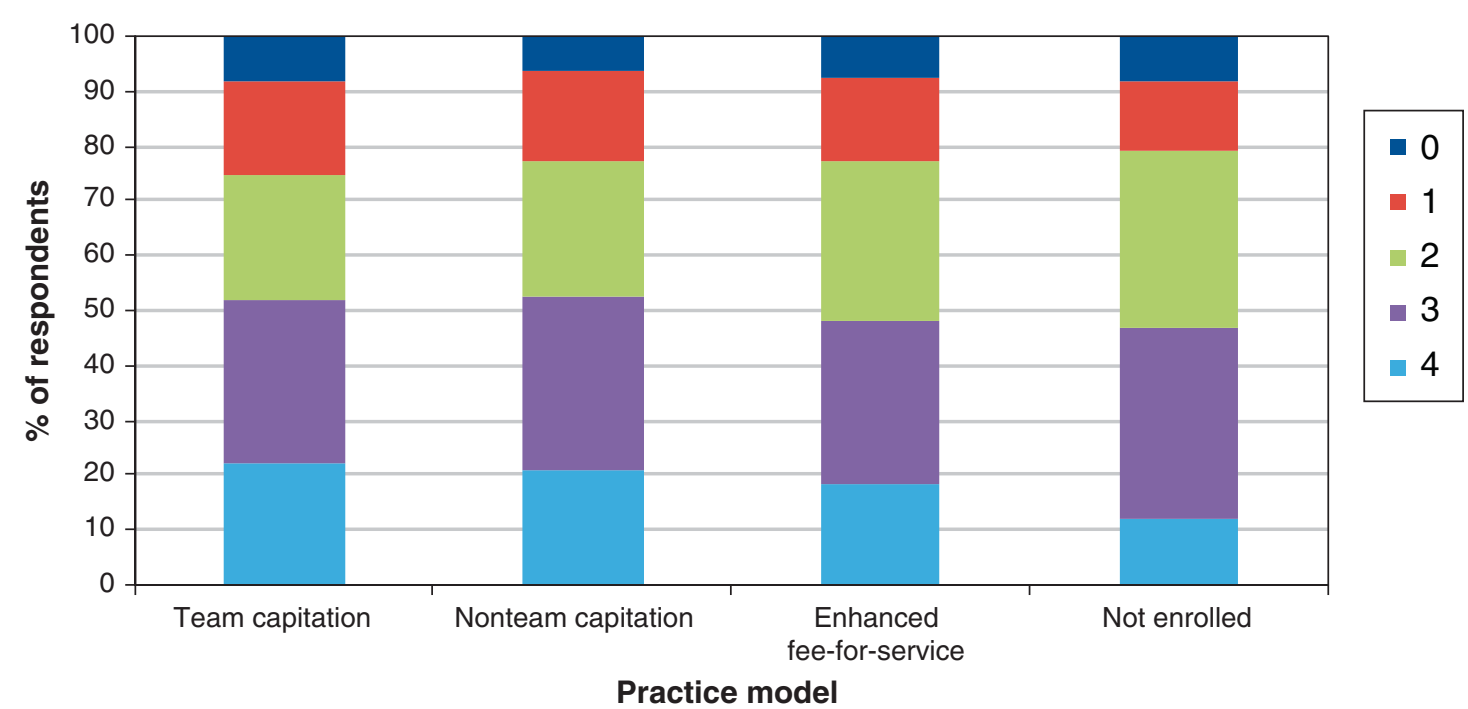

Figure 2: Proportion of respondents in survey wave 15-16 who reported favourable access to the 4 questions related to timely access to primary care (same-day or next-day access when sick, satisfaction with time to visit when sick, telephone access and awareness of after-hours clinic), stratified by practice model (A) $(n=1486)$ and rurality (B) $(n=1540)$. 


\begin{tabular}{|c|c|c|c|}
\hline \multirow{2}{*}{$\begin{array}{l}\text { Satisfied with } \\
\text { time to visit } \\
\text { when sick }\end{array}$} & \multicolumn{3}{|c|}{$\begin{array}{l}\text { Same-day/next-day appointment; } \\
\text { no. }(\%) \text { of respondents* }\end{array}$} \\
\hline & Yes & No & Total \\
\hline Yes & $806(50.1)(91.5)$ & 803 (49.9) (56.8) & 1609 \\
\hline No & 75 (10.9) (8.5) & $610(89.0)(43.2)$ & 685 \\
\hline Total & 881 & 1413 & 2294 \\
\hline
\end{tabular}

nonteam capitation 51\% [adjusted OR 1.90, 95\% CI $1.76-$ 2.04], enhanced fee-for service 34\% [reference]). In small towns, the relations between model and same-day or nextday access and after-hours awareness were similar to those noted in big cities.

Respondents in team capitation models reported more favourable telephone access in big cities and less favourable telephone access in small towns relative to respondents in enhanced fee-for-service models; there were no other differences in reported telephone access by model. There were no significant differences by model for satisfaction with time to an appointment. Overall, there were also no significant differences by model for respondents in rural areas for any of the 4 access questions. Full parameter estimates are presented in Appendix 2, Supplemental Table S3.

\section{Interpretation}

We found that, compared to respondents enrolled to physicians paid primarily by fee-for-service, respondents enrolled to physicians paid mostly via capitation were significantly less likely to report having a same-day or next-day visit when sick but were significantly more likely to report that their provider had an after-hours clinic. Respondents in teambased capitation practices reported somewhat better sameday or next-day access than respondents in nonteam capitation practices and were more likely to report that their

\begin{tabular}{|c|c|c|c|c|c|c|}
\hline \multirow[b]{2}{*}{ Access aspect } & \multicolumn{5}{|c|}{ Model; no. (\%) of respondents } & \multirow[b]{2}{*}{$p$ value } \\
\hline & All respondents & Team capitation & $\begin{array}{l}\text { Nonteam } \\
\text { capitation }\end{array}$ & $\begin{array}{c}\text { Enhanced } \\
\text { fee-for-service }\end{array}$ & Not enrolled & \\
\hline \multicolumn{7}{|c|}{$\begin{array}{l}\text { Same-day/next-day access } \\
\text { when sick }\end{array}$} \\
\hline Overall & $6493(40.9)$ & 2147 (38.5) & $1711(38.8)$ & $1868(45.1)$ & $767(43.4)$ & $<0.001$ \\
\hline Big cities & $4406(43.2)$ & $1074(42.5)$ & $1249(39.8)$ & 1505 (45.7) & $578(46.1)$ & $<0.001$ \\
\hline Small towns & $1605(40.0)$ & $795(40.1)$ & $377(36.9)$ & $310(44.9)$ & $123(39.0)$ & $<0.001$ \\
\hline Rural & $482(28.8)$ & $278(26.2)$ & $85(33.5)$ & $53(33.1)$ & $66(33.3)$ & 0.04 \\
\hline \multicolumn{7}{|c|}{$\begin{array}{l}\text { Satisfaction with time to visit } \\
\text { when sick } \dagger\end{array}$} \\
\hline Overall & $1576(70.1)$ & $554(69.9)$ & $470(69.4)$ & $372(70.1)$ & $180(72.9)$ & 0.9 \\
\hline Big cities & $1023(71.2)$ & $270(73.8)$ & $331(69.5)$ & $296(69.8)$ & $126(74.1)$ & 0.3 \\
\hline Small towns & $400(69.8)$ & $194(69.8)$ & $110(67.9)$ & $63(74.1)$ & $33(68.8)$ & 0.9 \\
\hline Rural & $153(64.0)$ & $90(60.4)$ & $29(74.4)$ & $13(59.1)$ & $21(72.4)$ & 0.4 \\
\hline \multicolumn{7}{|c|}{ Telephone access } \\
\hline Overall & $13571(78.5)$ & $5239(78.5)$ & $4004(79.4)$ & 2964 (78.3) & $1364(76.5)$ & 0.001 \\
\hline Big cities & $8100(78.8)$ & $2283(80.8)$ & $2730(79.2)$ & 2201 (77.3) & $886(76.2)$ & 0.003 \\
\hline Small towns & $3919(79.0)$ & $1982(78.2)$ & $997(79.6)$ & 627 (81.9) & $313(76.9)$ & $<0.001$ \\
\hline Rural & $1552(76.2)$ & $974(74.2)$ & 277 (81.2) & $136(79.5)$ & $165(77.5)$ & 0.07 \\
\hline \multicolumn{7}{|c|}{$\begin{array}{l}\text { Awareness of after-hours } \\
\text { clinic }\end{array}$} \\
\hline Overall & $13528(42.2)$ & $5492(48.1)$ & $4213(47.4)$ & $2710(34.3)$ & $1113(29.1)$ & $<0.001$ \\
\hline Big cities & 8880 (44.9) & 2832 (58.7) & $3146(51.0)$ & $2125(34.4)$ & $777(30.0)$ & $<0.001$ \\
\hline Small towns & 3701 (43.8) & 2061 (49.5) & $900(42.5)$ & $507(36.6)$ & $233(29.8)$ & $<0.001$ \\
\hline Rural & 947 (24.7) & $599(24.6)$ & $167(27.9)$ & 78 (22.9) & $103(22.3)$ & 0.008 \\
\hline
\end{tabular}


Access aspect

Same-/next-day access when sick

Satisfaction with time to visit when sick

Telephone access

Awareness of after-hours clinic
Rurality

Big cities

Rura

Small towns

Big cities

Rural

Big cities

Rural

Big cities

Rural

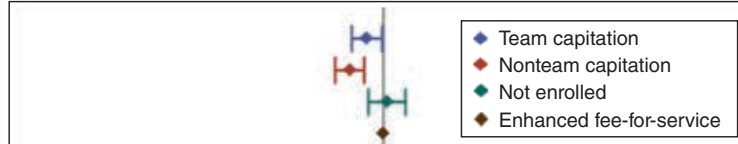

- Enhanced fee-for-service
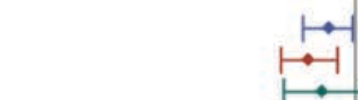

$\longrightarrow$

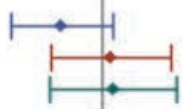

$\rightarrow$

1
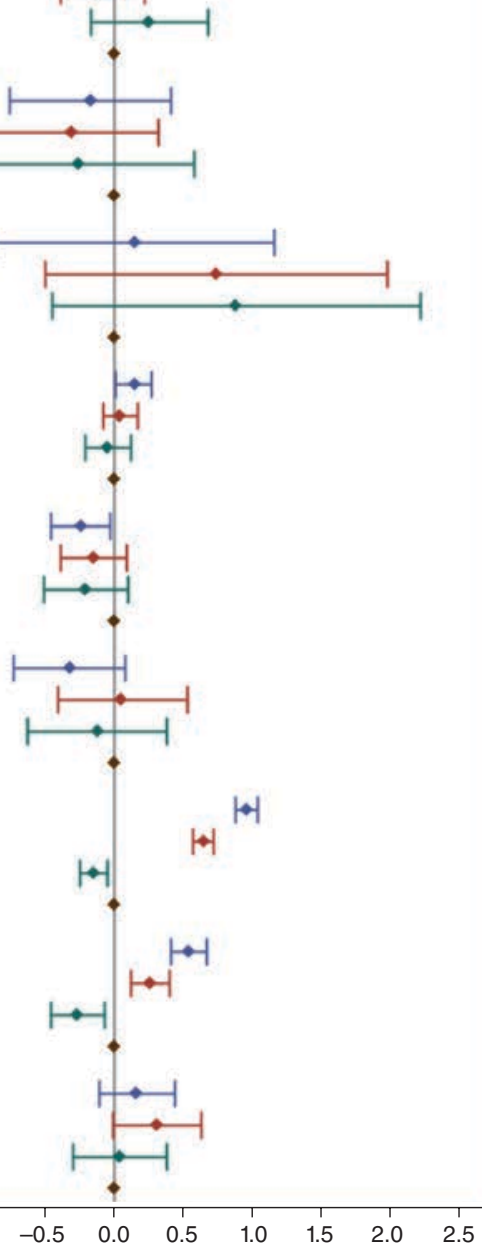

$+1$

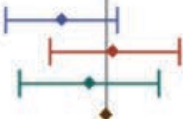

$+$

Log OR

Figure 3: Adjusted log of odds ratios (ORs) for respondents in different practice models who reported favourable access, stratified by rurality. All models were adjusted for age, sex, education, tight financial situation, self-rated health, comorbidity and health plan registration within the previous 10 years. Full parameter estimates are presented in Appendix 2, Supplemental Table S3. Error bars represent 95\% confidence intervals.

provider had an after-hours clinic. These differences existed both in big cities and small towns even after adjustment for respondent demographic characteristics. Reported telephone access and satisfaction with time to visit were moderate to high overall, with few consistent differences by practice model. Respondents in rural areas consistently reported 
much poorer access. Very few respondents reported emailing with their provider or using online booking.

Our results highlight the importance of measuring timely access in primary care in multiple ways. Our finding of low reported same-day or next-day visits when sick echoes other reports. ${ }^{3}$ However, one-third of our respondents said they were satisfied with time to visit even though the visit was not on the same or next day. This discrepancy highlights the limitations of evaluating access or targeting related improvements with the measure of same-day or next-day visit, a measure favoured by news media and politicians. ${ }^{20,21}$ Even so, it is concerning that patients enrolled to capitation practices reported poorer same-day or next-day access than those in enhanced fee-for-service models, given the goals of reforms and the higher relative income of physicians paid by capitation..$^{8,14}$ Reduction in service is a known risk of capitation. ${ }^{22}$

Our finding of relatively poor same-day or next-day access for respondents enrolled to team-based models was contrary to our expectation. Other investigators have reported how enhanced roles for nonphysician health care professionals can improve access, ${ }^{11,12,23}$ which suggests that team-based care can be further optimized in Ontario. In Quebec, team-based care was introduced without physician payment reform and has been associated with a decrease in the rate of primary care visits but not emergency department visits; ${ }^{24}$ however, it is unclear what effect it has had on patient-reported access. In the United States, evaluations of patient-centred medical homes have shown improvements in timely access. ${ }^{25}$ This suggests that Ontario may need to go further to support practices to adopt medical home principles and related accountability.

We found that respondents who were not enrolled had lower awareness of after-hours clinics but otherwise reported access similar to that reported by those enrolled to enhanced fee-for-service physicians. However, previous work suggests that patients who are not enrolled are less likely than enrolled patients to receive effective care. ${ }^{15}$ In the current study, respondents with fair health and a tight, very tight or poor financial situation generally reported poorer access in all categories. New residents of Ontario and those who did not speak English reported higher rates of same-day or next-day visits but poorer access in other categories compared to longterm residents and those who spoke English, respectively. These findings suggest that some newcomers may be seeing physicians practising walk-in style but may also be having difficulties navigating the health care system. In our setting, the strongest determinant of access was rurality, an unsurprising finding given the known challenges with rural physician supply.

Team-based practices likely need to strengthen efforts to have nonphysician health care professionals share the care to improve access. ${ }^{12}$ Policy-makers should carefully consider how to incentivize timely visits for capitation practices given the financial disincentive to provide timely access inherent in capitation payment. More needs to be done to support adoption of email and virtual care in all practices. Future changes to physician payment and organization should be evaluated prospectively to understand their impact on access.

\section{Limitations}

Our study has notable limitations. First, survey respondents underrepresented some patient groups, including those living in lower-income neighbourhoods and newcomers to Canada. We suspect survey response bias may have led to more favourable reporting of timely access overall. Second, our study was cross-sectional. We found some differences in reported access by practice model, but it is unclear whether these differences predated physicians' joining new models. Third, joining new practice models was voluntary, and the differences we found may relate in part to differences between physicians who chose to join specific models that are hard to measure. Fourth, the most recent survey data available to us for analysis was from 2015, and our findings may not reflect the current state. Finally, our analysis was limited by smaller samples in rural areas and for assessing satisfaction with time to visit.

\section{Conclusion}

We found that, compared to respondents enrolled to physicians paid primarily by fee-for-service, those enrolled to physicians paid mostly by capitation were less likely to report a same-day or next-day visit when sick but more likely to report that their provider had an after-hours clinic. Within capitation practices, same-day or next-day access was somewhat better and after-hours awareness much better for respondents enrolled to practices that received funding for nonphysician health care professionals than for those that did not. Our findings suggest that timely access to primary care is a nuanced concept and that multiple measures informed by patients are needed to understand health care system performance.

\section{References}

1. Starfield B, Shi L, Macinko J. Contribution of primary care to health systems and health. Milbank Q 2005;83:457-502.

2. Starfield B. Primary care: balancing bealth needs, services, and technology. Oxford (UK): Oxford University Press; 1998.

3. How Canada compares: results from the Commonwealth Fund's 2016 international bealth policy survey of adults in 11 countries. Ottawa: Canadian Institute for Health Information; 2017.

4. Hutchison B, Levesque JF, Strumpf E, et al. Primary health care in Canada: systems in motion. Milbank Q 2011;89:256-88.

5. Iglehart JK. No place like home - testing a new model of care delivery. $N$ Engl 7 Med 2008;359:1200-2.

6. American Academy of Family Physicians (AAFP); American Academy of Pediatrics (AAP); American College of Physicians (ACP); American Osteopathic Association (AOA). Joint principles of the Patient-Centered Medical Home. Leawood (KS): American Academy of Family Physicians; 2007. Available: www.aafp.org/dam/AAFP/documents/practice_management/pcmh/initiatives/ PCMHJoint.pdf (accessed 2018 Dec. 18).

7. Family practice: the patient's medical home. Mississauga (ON): College of Family Physicians of Canada; 2011.

8. Hutchison B, Glazier R. Ontario's primary care reforms have transformed the local care landscape, but a plan is needed for ongoing improvement. Health Aff (Millwood) 2013;32:695-703.

9. Gosden T, Forland F, Kristiansen IS, et al. Capitation, salary, fee-for-service and mixed systems of payment: effects on the behaviour of primary care physicians. Cochrane Database Syst Rev 2000;(3):CD002215.

10. Bodenheimer T, Ghorob A, Willard-Grace R, et al. The 10 building blocks of high-performing primary care. Ann Fam Med 2014;12:166-71.

11. McCarthy D, Mueller K, Tillmann I. Group Health Cooperative: reinventing primary care by connecting patients with a medical home. New York: The Commonwealth Fund; 2009.

12. Sinsky CA, Willard-Grace R, Schutzbank AM, et al. In search of joy in practice: a report of 23 high-functioning primary care practices. Ann Fam Med 2013;11:272-8. 
13. Table 17-10-0005-01: Population estimates on July 1st, by age and sex. Ottawa: Statistics Canada; 2020. Available: https://www150.statcan.gc.ca/t1/tbl1/en/tv. action?pid $=1710000501$ \& pickMembers $\% 5 B 0 \% 5 \mathrm{D}=1.7$ \&pickMembers $\% 5 \mathrm{~B} 1 \%$ $5 \mathrm{D}=2.1$ (accessed 2018 Dec. 18)

14. Henry DA, Schultz SE, Glazier RH, et al. Payments to Ontario physicians from Ministry of Health and Long-Term Care sources, 1992/93 to 2009/10: ICES investigative report. Toronto: ICES; 2012.

15. Kiran T, Kopp A, Glazier RH. Those left behind from voluntary medical home reforms in Ontario, Canada. Ann Fam Med 2016;14:517-25.

16. Green ME, Gozdyra P, Frymire E, et al. Geographic variation in the supply and distribution of comprehensive primary care physicians in Ontario, 2014/15. Toronto: ICES; 2017.

17. Glazier RH, Zagorski BM, Rayner J. Comparison of primary care models in Ontario by demographics, case mix and emergency department use, 2008/09 to 2009/10: ICES investigative report. Toronto: ICES; 2012.

18. Kralj B. Measuring rurality - RIO2008 BASIC: methodology and results. Toronto: Ontario Medical Association; 2009.

19. Ray JG, Vermeulen MJ, Schull MJ, et al. Results of the Recent Immigrant Pregnancy and Perinatal Long-term Evaluation Study (RIPPLES). CMAf 2007;176:1419-26.

20. Ferguson R. Ontario wants more patients to get same-day or next-day appointments, Ontario health minister says. OurWindsor.ca 2015 Feb. 3. Available: www.ourwindsor.ca/news-story/5319457-ontario-wants-more-patients-to-get -same-day-or-next-day-appointments-ontario-health-minister-says/ (accessed 2018 Dec. 18)

21. Grant K. How quickly can you see a doctor? Study shows Canada lags behind other nations on timely access. Globe and Mail [Toronto] 2017 Feb. 16, updated 2017 Nov. 12. Available: www.theglobeandmail.com/life/health-and-fitness/ health/how-quickly-can-you-see-a-doctor-study-shows-canada-lags-behind-other -nations-on-timelyaccess/article34043606/ (accessed 2018 Dec. 18).

22. Goodson JD, Bierman AS, Fein O, et al. The future of capitation: the physician role in managing change in practice. 7 Gen Intern Med 2001;16:250-6.

23. Ghorob A, Bodenheimer T. Sharing the care to improve access to primary care. N Engl 7 Med 2012;366:1955-7.

24. Strumpf E, Ammi M, Diop M, et al. The impact of team-based primary care on health care services utilization and costs: Quebec's family medicine groups. 7 Health Econ 2017;55:76-94.

25. Nielsen M, Olayiwola JN, Grundy P, et al. The patient-centered medical home's impact on cost \& quality: an annual update of the evidence, 2012-2013. Washington: Patient-Centered Primary Care Collaborative; 2014

Affiliations: Department of Family and Community Medicine (Kiran, Glazier) and Centre for Urban Health Solutions (Kiran, Glazier), Li Ka Shing Knowledge Institute, St. Michael's Hospital; Department of Family and Community Medicine (Kiran, Glazier), Faculty of Medicine, University of Toronto; ICES Central (Kiran, Schultz, Kopp, Glazier); Ontario Health, Quality Division (formerly Health Quality Ontario) (Kiran, Yeritsyan, Wissam), Toronto, Ont.; ICES Queen's (Green, DeWit,
Khan); Centre for Health Services and Policy Research (Green), Queen's University, Kingston, Ont.

Contributors: Tara Kiran and Richard Glazier conceived of the study. Tara Kiran, Michael Green, Yvonne DeWit, Sue Schultz, Alexander Kopp, Naira Yeritsyan, Haj Wissam and Richard Glazier designed the study. Yvonne DeWit and Shahriar Khan analyzed the data. Tara Kiran drafted the manuscript. All of the authors interpreted the data, revised the manuscript critically for important intellectual content, approved the final version to be published and agreed to be accountable for all aspects of the work.

Funding: This study was supported by ICES, which is funded by an annual grant from the Ontario Ministry of Health and Long-Term Care (MOHLTC), by the Toronto Central Local Health Integration Network and by the INSPIRE Primary Health Care Research Program, which is funded through the Ontario MOHLTC Health System Research Fund. Tara Kiran and Richard Glazier are supported as Clinician Scientists by the Department of Family and Community Medicine at the University of Toronto and at St. Michael's Hospital. Tara Kiran is the Fidani Chair in Improvement and Innovation at the University of Toronto. She is also supported by the Canadian Institutes of Health Research and Ontario Health, Quality Division as an Embedded Clinician Researcher. Michael Green is supported by the Brian Hennen Chair in Family Medicine at Queen's University.

Data sharing: The data set from this study is held securely in coded form at ICES. Although data-sharing agreements prohibit ICES from making the data set publicly available, access may be granted to those who meet prespecified criteria for confidential access, available at www.ices.on.ca/DAS. The full data set creation plan and underlying analytic code are available from the authors on request, with the understanding that the computer programs may rely on coding templates or macros that are unique to ICES and are therefore inaccessible or may require modification.

Disclaimer: This study was supported by ICES, which is funded by an annual grant from the Ontario Ministry of Health and Long-Term Care (MOHLTC). The opinions, results and conclusions reported in this article are those of the authors and are independent from the funding sources. No endorsement by ICES, the Toronto Central Local Health Integration Network or the Ontario MOHLTC is intended or should be inferred.

Supplemental information: For reviewer comments and the original submission of this manuscript, please see www.cmajopen.ca/content/8/2/ E328/suppl/DC1. 